J. clin. Path. (1957), 10, 168.

\title{
A CASE OF ANURIA DUE TO DESTRUCTION OF GLOMERULI
}

\author{
BY \\ JOHN C. DICK \\ From the Department of Pathology, Stobhill General Hospital, Glasgow
}

(RECEIVED FOR PUBliCATION MAY 9, 1956)

The following case of anuria presented an uncommon renal lesion, and, in view of the nature of this lesion, the patient's survival under Bull's therapy for 25 days is of considerable interest.

\section{Clinical Course}

The patient, a woman of 45 years, was admitted to the Department of Dermatology on October 8, 1954, giving a history of a rash of two months' duration. She had had three distinct attacks of "skin rash" over the past three years, one each ascribed to measles, wool irritation, and fish allergy. Her general health was otherwise good, although she took an occasional powder containing aspirin to relieve headaches. The present eruption appeared first on the skin of the neck and later spread to the face, shoulders, trunk, arms, and thighs, with considerable attendant itching. On admission, it was erythematous with slight desquamation over the affected areas and an additional papular element on the arms and thighs: several purpuric and striate lesions were present on the skin of the upper back: the axillary lymph nodes were moderately enlarged.

Blood examination: Hb 12.7 g., R.B.C. $3.47 \mathrm{~m} . /$ c.mm., P.C.V. $39 \%$, M.C.V. 112 c $\mu$., M.C.H.C. $32.5 \%$, W.B.C. $2,500 /$ c.mm. (polymorphs $49 \%$, monocytes $2 \%$, basophils $2 \%$, eosinophils $3 \%$ ), cells normal. Blood pressure was $124 / 75 \mathrm{~mm}$. $\mathrm{Hg}$. At this time, and again on October 23 , the urine was normal.

The antihistamine, $\beta$-dimethylaminoethyl benzhydryl ether hydrochloride, $200 \mathrm{mg}$. daily, was given by mouth in divided doses, with adequate fluid intake, complete rest in bed, and local emollient applications. Progress was satisfactory for three weeks. On November 2, however, she had some fever, complained of nausea, and vomited. From then, she passed very small amounts of urine and none at all on November 5, even by catheter. Next day she was transferred to a medical ward. Post-renal obstruction was excluded by retrograde pyelography, so an intragastric drip was set up with the intention of administering $800 \mathrm{ml}$. of $40 \%$ glucose daily. This led to such frequent vomiting that an intracaval drip was started on November 8. Management was now comparatively straightforward with $700 \mathrm{ml}$. of $50 \%$ glucose and sodium lactate when required (Bull, 1952). Never more than $35 \mathrm{ml}$. of urine was passed on any one day, the urine containing albumin, red blood cells, and about $0.59 \%$ urea. She died on November 27 , some 25 days after the start of the anuria. During the last five days of life she was drowsy, showed uraemic twitching, and complained of pain in the front of the chest, due to pericarditis. The course of the illness and biochemical data are given in the table.

TABLE

ABSTRACT OF DAILY RESULTS

\begin{tabular}{|c|c|c|c|c|}
\hline Date & $\begin{array}{c}\text { Blood } \\
\text { Urea } \\
\text { (mg./100 ml.) }\end{array}$ & $\begin{array}{c}\text { Potassium } \\
(\mathrm{mg} \cdot / 100 \mathrm{ml} . \\
\text { and } \\
\mathrm{mEq} \cdot / 1 .)\end{array}$ & $\begin{array}{c}\text { Alkali } \\
\text { Reserve } \\
\text { (Vol. CO } \\
100 \mathrm{ml} / \text { and } \\
\text { mEq./l.) }\end{array}$ & Notes \\
\hline $\begin{array}{r}6 / 11 / 54 \\
9 / 11 / 54 \\
13 / 11 / 54\end{array}$ & $\begin{array}{r}172 \\
244 \\
-\end{array}$ & $\begin{array}{l}22.0(5.6) \\
21.0(5.4) \\
24.0(6.2)\end{array}$ & $\begin{array}{l}28(12.6) \\
51(23.0) \\
47(21 \cdot 2)\end{array}$ & \multirow{2}{*}{$\begin{array}{l}\text { Sod. lactate } \\
\text { Resonium } \\
\text { A. } \\
\text { Died }\end{array}$} \\
\hline $\begin{array}{l}20 / 11 / 54 \\
25 / 11 / 54 \\
27 / 11 / 54\end{array}$ & $\begin{array}{r}464 \\
512 \\
-\end{array}$ & $\begin{array}{c}17.0(4.4) \\
18.6(4.8) \\
-\end{array}$ & $\begin{array}{l}44(19 \cdot 8) \\
44(19 \cdot 8)\end{array}$ & \\
\hline
\end{tabular}

\section{Necropsy}

Necropsy was performed 16 hours after death. The body was that of a short, stout woman with thick subcutaneous fat. Slight ankle oedema was present and there were numerous petechial haemorrhages round the shoulders. There was slight scaling of the skin, without discoloration or ulceration, over the face, shoulders, chest, and legs. The pericardium contained an exudate of clear yellow fluid with thick, stringy, fibrinous material, some organized to dense fibrous tissue. The chambers and valves of the heart were normal, though the muscle was soft, flabby and showed slight fatty infiltration from the surface. The pleurae were normal. Most of the lung tissue was well aerated and only slightly congested, though in the lower lobes and posterior parts of the other lobes there were numerous small, haemorrhagic infarcts. There was some varicosity of the veins 


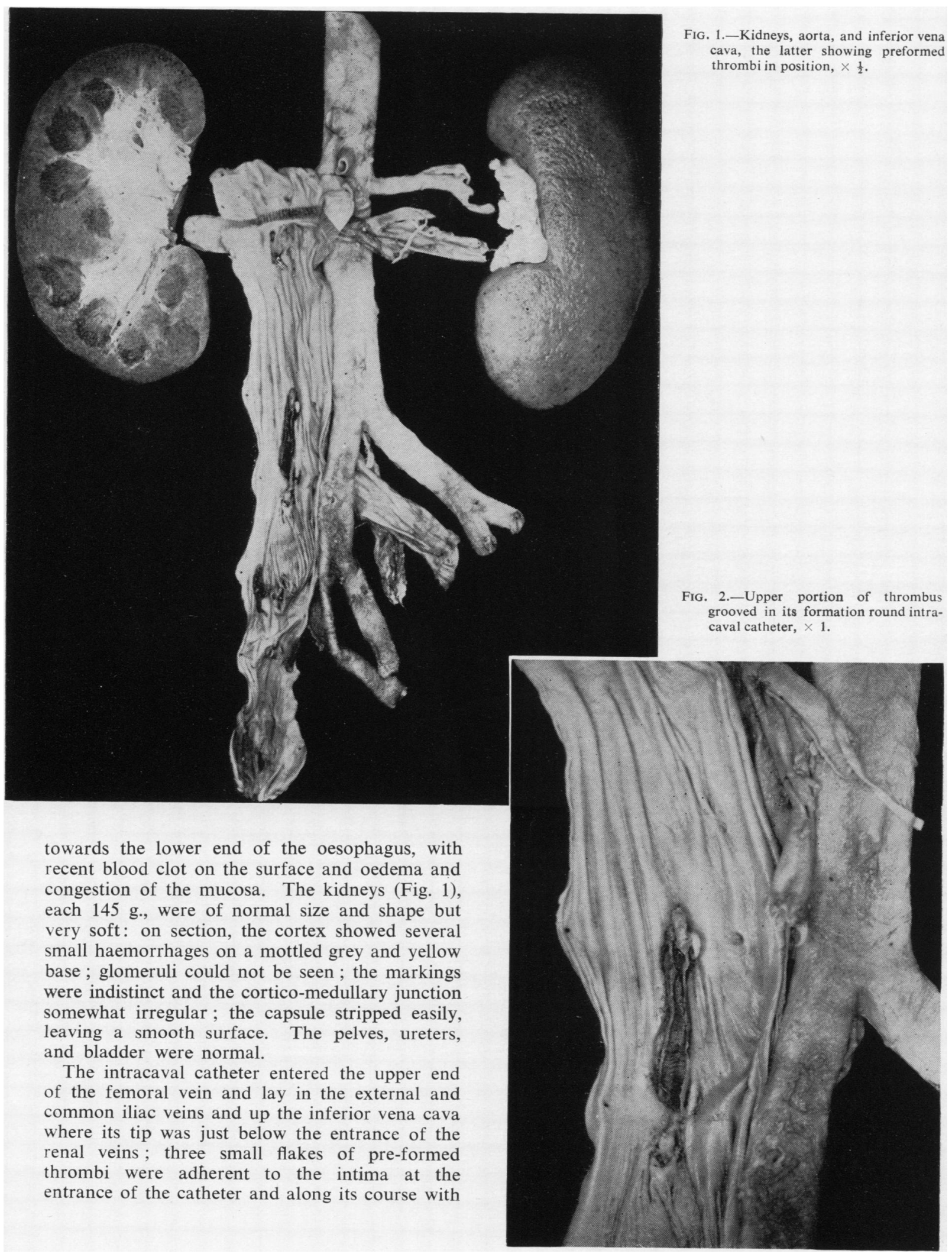




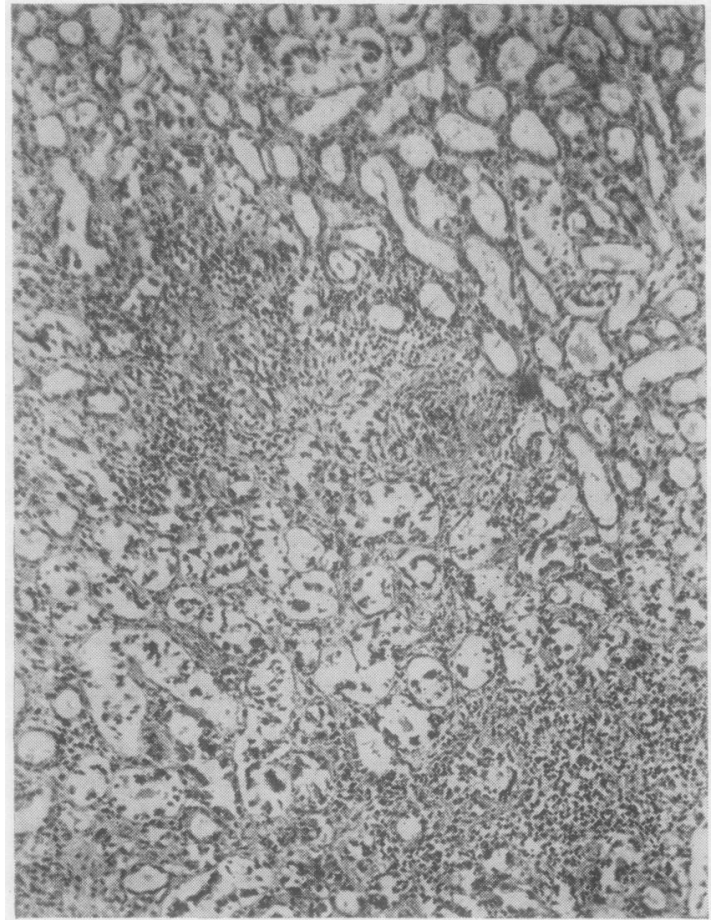

Fig. 3.-General view of the cortex, showing destruction of glomeruli. H. and $E$., $\times 100$.

another longer $(4 \mathrm{~cm}$.) grooved thrombus near the upper end (Fig. 2), none causing obstruction to the venous channel. The wall of the vein showed no thickening or other abnormality. The other organs in the abdominal cavity were normal.

The brain was pale and slightly oedematous, but showed no other changes.

Histology. - Throughout both kidneys, all glomeruli were almost completely destroyed (Fig. 3). A very few capillary loops were seen in some of the remains of the glomeruli (Fig. 4), but most of the capsule and any traces of capsular epithelium were unrecognizable (Figs. 5 and 6), while nothing was left of many of the glomeruli but loose fibrous tissue (Fig. 7). There was a variable amount of cellular infiltration around, mostly very scanty, though sometimes quite abundant, consisting mainly of round cells with very few polymorphs, plasma cells or macrophages, and no eosinophils. As expected in a subject of this age, a few glomeruli had been hyalinized before the onset of this condition and these structures were either unaffected or even somewhat loosened with some round cell infiltration around (Fig. 8). These points were confirmed by the use of Van Gieson's

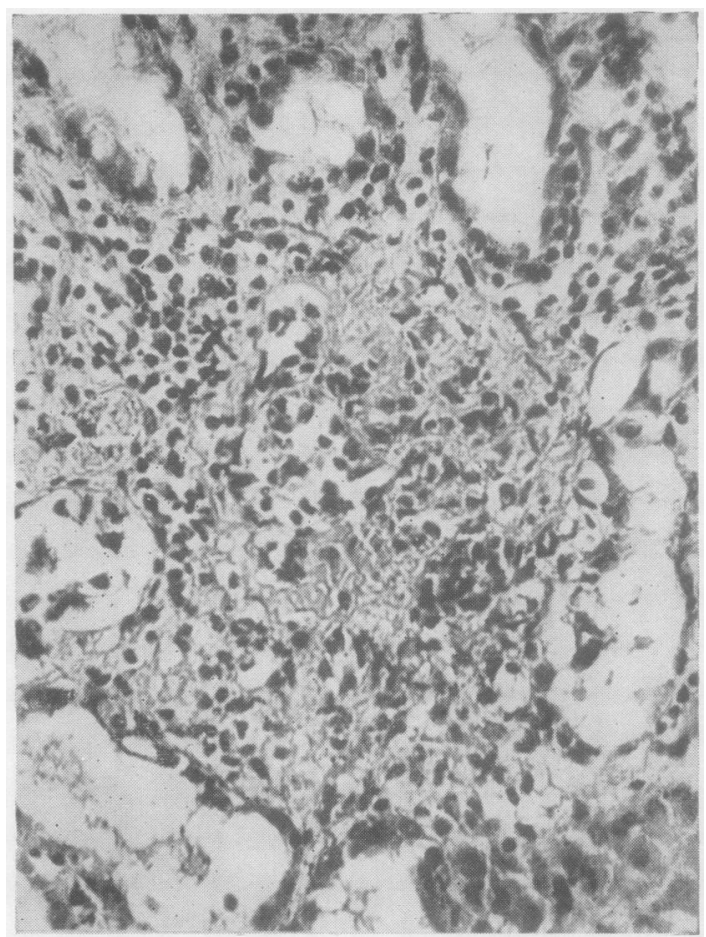

FIG. 4.-Destroyed glomerulus, with remains of capillary loops, no evidence of capsule and only a little round cell infiltration. H. and E., $\times 300$.

(Figs. 9 and 10) and Weigert's fibrin (Fig. 11) staining methods, and by these and reticulin staining (Fig. 12) there was no evidence of thrombosis in the capillary loops, reduplication of capsular epithelium, or increased fibrosis in or around the glomeruli. It appeared that the capsule became fibrinous and then disappeared while capsular epithelium and glomerular capillaries were also disappearing.

The afferent and efferent vessels shared in this disappearing phenomenon and, apart from the vague appearance in a few instances as shown in Fig. 6, they could not be distinguished. Larger arteries, however, were normal and showed no reduplication of elastic tissue or increased fibrosis in media or intima; no necrosis of the media or lesions of polyarteritis nodosa were found. Most of the convoluted tubules and limbs of Henle showed only cloudy swelling, perhaps atrophic, perhaps autolytic, though a few contained hyaline or haemoglobin casts. There was no fat nor hyaline droplet degeneration in the epithelial cells. In the collecting tubules, there was much desquamation, some atrophy and groups of multinucleated epithelial masses, while they sometimes 


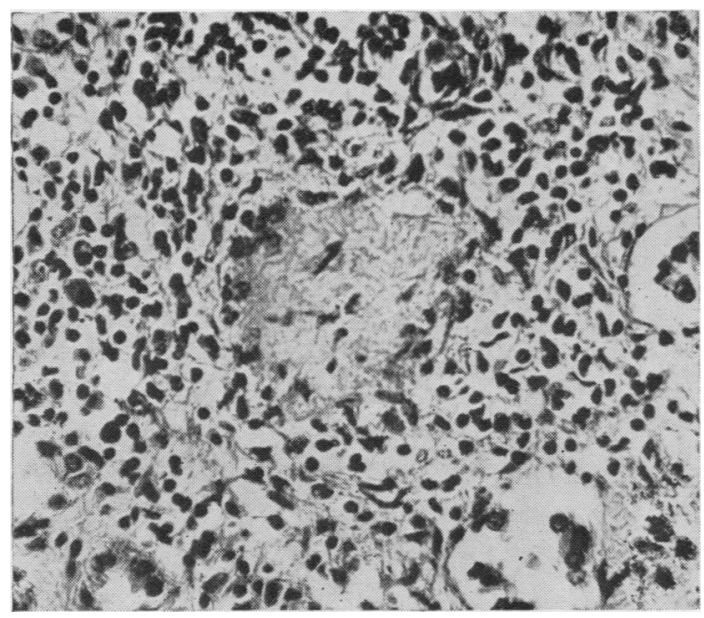

FIG. 5.-Remains of glomerulus with no evidence of capillary loops and little of capsular epithelium. H. and E., $\times 300$.

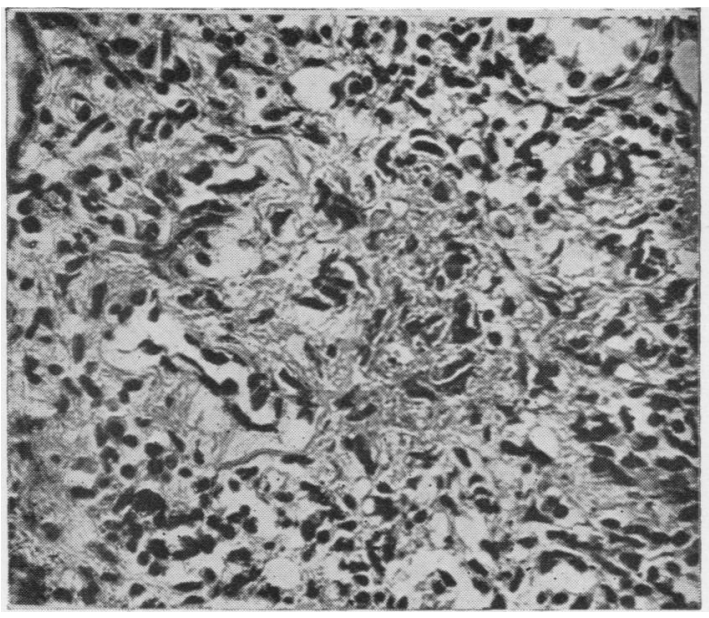

FIG. 6.-Destroyed glomerulus with little evidence of capsular epithelium, no capillary loops, but possibly an afferent or efferent vessel still present. H. and $E ., \times 300$.

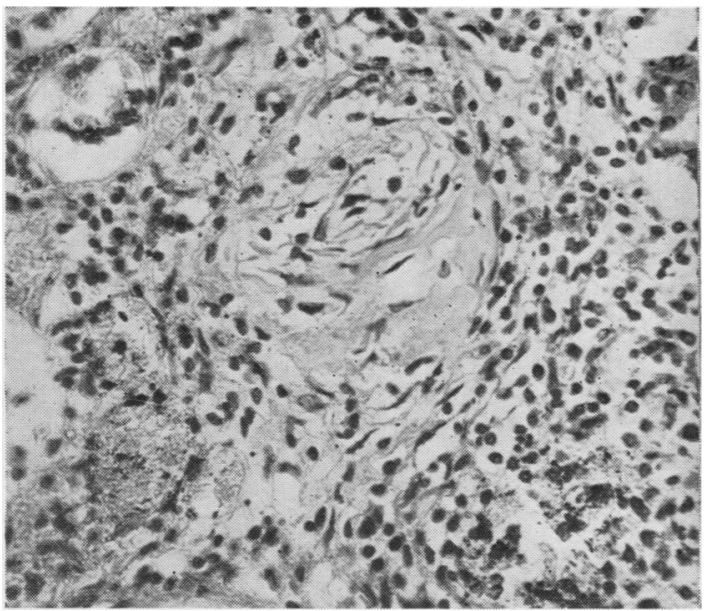

FIG. 8.-Partially hyalinized glomerulus, with some loose fibrous tissue and round cell infiltration around. H. and E., $\times 360$.

bundles: no necrosis of any of the formed elements was seen: the cells in the infiltration consisted of small mononuclears, a few large macrophages, polymorphs, eosinophils, and a few lymphocytes; they varied considerably in proportion in different foci, some resembling minute abscesses, others almost like the cellular content of an Aschoff nodule, but no consistent or specific appearance could be detected.

In the lungs, the small dark areas were confirmed as recent bland infarcts, probably the result of embolism by small portions of thrombus from the inferior vena cava. In the lower end of the 


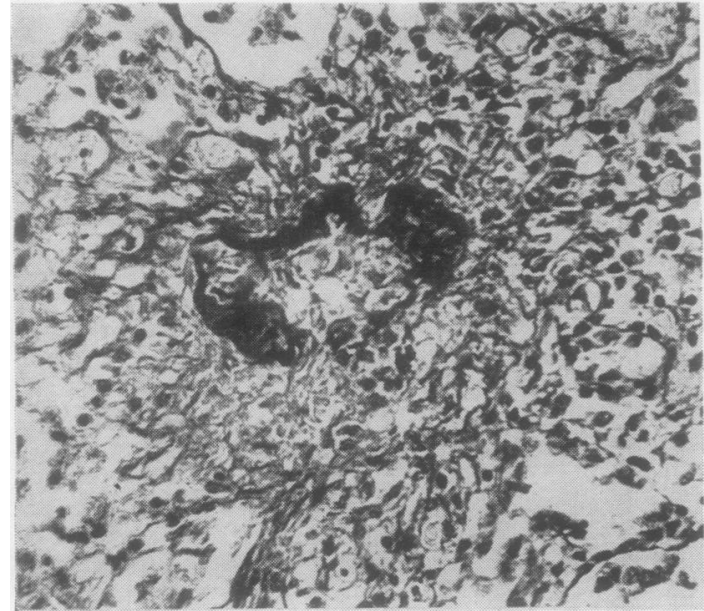

FiG. 9.-Wrinkled remains of capsule staining strongly with fuchsin. H. and V.G., $\times 300$.
FIG. 11.-Similar magnification view to show some capsular remains staining positively for fibrin. Weigert's fibrin method, $\times 100$.

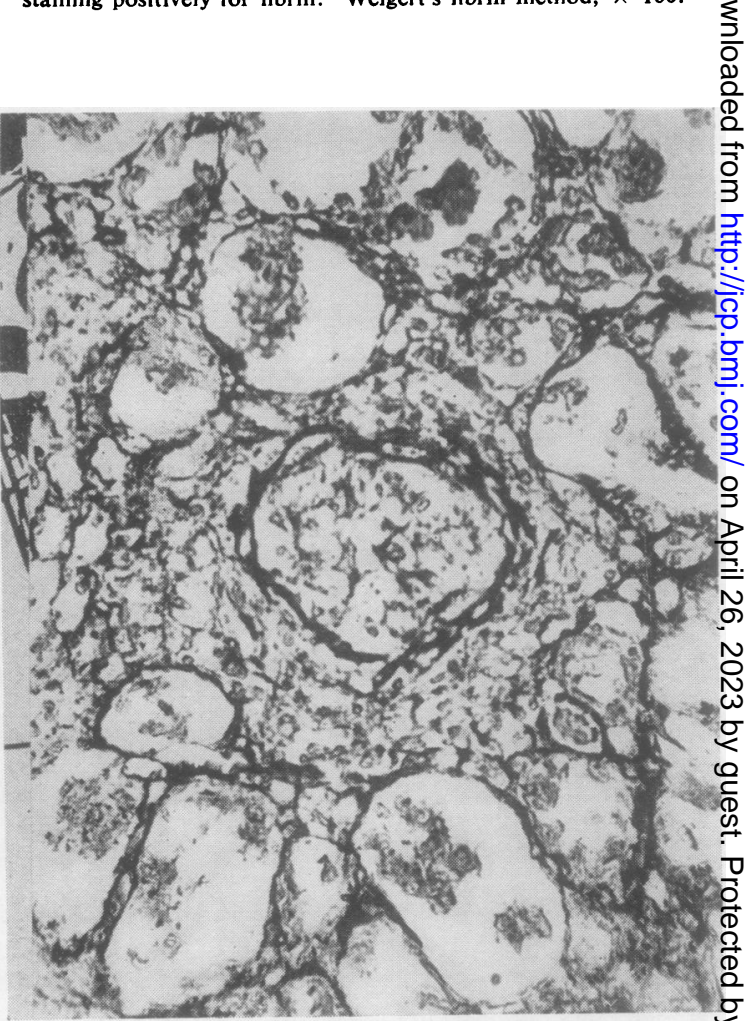

FIG. 12.-No new formation of reticulin in disappearing glomerulus

Gordon and Sweet's reticulin stain, $\times 300$.

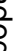

FIG. 10.-Lower magnification view showing varying amounts of fuchsinophil material in glomerular remains. H. and V.G., $\times 100$.

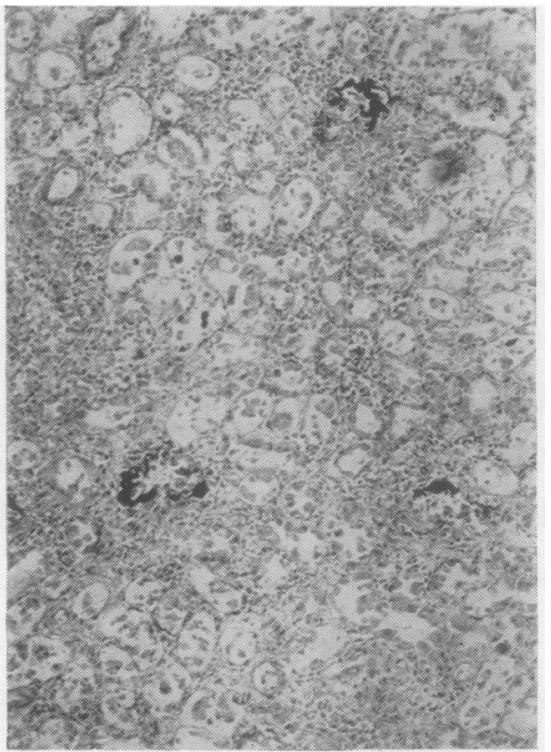

$\sum^{2}$

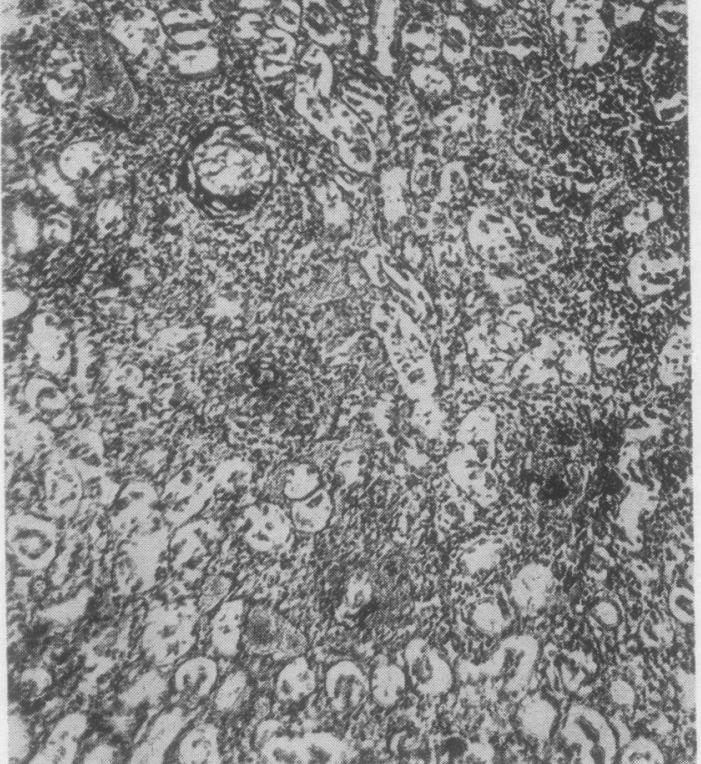


oesophagus, there was ante-mortem digestion of the mucosa and oedema and autolysis extending into the submucosa, but no vascular changes. The mesenteric and para-aortic lymph nodes were only slightly enlarged yet showed considerable upset to their architecture: there was complete loss of germinal follicles, a few being replaced by masses of hyaline eosinophilic material, the remainder having disappeared; marked sinus hyperplasia was present and elsewhere there was infiltration with eosinophils and plasma cells in no specific pattern.

Sections of skin from the anterior chest wall and medial side of the leg showed the features of seborrhoeic dermatitis and afforded no suggestion of generalized lupus erythematosus.

No significant abnormalities were seen in liver, spleen, pancreas, suprarenals, or thyroid.

\section{Discussion}

The importance of this case lies in the nature of the kidney lesion. It was realized that the long survival time ( 25 days) after the onset of anuria may have had a considerable effect on the changes found in the kidneys. Most cases which are maintained on Bull's therapy following anuria for shock, incompatible blood transfusion, drug sensitivity, etc., are suffering from tubular necrosis, and glomerular lesions are minimal (Bull and Dible, 1953). In this case, however, the tubular lesions are relatively slight and the chief damage is to the glomeruli, which now represent the later stages of a type of destruction, a description of which could not be found in the literature. Sections of the kidneys were submitted to Professor J. H. Dible, who wrote that he had never seen kidneys like this before and very kindly offered most of the following points for consideration.

(a) A type of acute nephritis was described by Dunn and Montgomery (1941) as acute necrotizing glomerulonephritis, associated with bilateral necrosis of the cortex and often associated with toxaemia of pregnancy though occurring quite apart from this condition. These authors attributed the lesions to extreme dilatation in the glomerular capillaries leading to loss of plasma and the development of thrombi in the capillaries, afferent arterioles, and larger vessels, and ultimately necrosis in the tufts. It is hardly conceivable that, if life could be prolonged for 25 days as in the present case, the necrotic tufts with fibrin thrombi could be autolysed (fibrosis would seem more probable) while thrombi in the afferent and larger arteries could not disappear nor would necrotic infarcts in the kidney cortex. Accord- ingly, it is unlikely that the present case is of this nature.

(b) In Henoch's purpura, kidney lesions may be very severe and their onset sudden. In the present case, there were petechial haemorrhages in the skin round the shoulders, though only terminally, and no generalized purpura. The kidney lesions in purpura, however, are of the productive type, as found in ordinary acute glomerulonephritis and the experimental type produced by specific sera, and no stage would fit in with the appearances found in the present case.

(c) Lupus erythematosus requires consideration in a patient with a fairly generalized skin eruption followed by kidney damage. The skin eruption, however, was both clinically and histologically a seborrhoeic dermatitis ; there was no accompanying endocarditis, though the non-specific nodules in the heart muscle may have been early stages of the myocardial lesions found by Gold and Gowing (1953). The alternative possibility that these foci of cellular infiltration were related to one of the varieties described in uraemia by Solomon, Roberts, and Lisa (1942) is not considered likely: there were no areas of necrosis to constitute them miliary myocardial necrosis, they were not sufficiently widely distributed to be an acute interstitial myocarditis, there were no acute miliary infarctions nor vascular lesions, and these authors found no lesion in their 50 cases dying from uraemia which could be considered characteristic of uraemia.

(d) The literature and varied microscopic renal lesions found in polyarteritis nodosa have recently been competently described by Davson, Ball, and Platt (1948) and later the macroscopic appearances (Wainwright and Davson, 1950). None of the lesions suggest any resemblance to the present case. Nevertheless, in three out of 10 cases of polyarteritis nodosa studied personally, some of the glomeruli showed the typical vascular lesion of polyarteritis applied to the glomerulus, wholly or partly, with the capsule taking the part of the vessel wall, leading to destruction of the capsule and loss of the glomerular capillaries with fibrosis and abundant cellular infiltration with polymorphs and round cells (probably the lesion described by Davson et al. (1948) as periglomerular granulomatous foci in their Cases 7, 8, and 9). In a small proportion of glomeruli, this process occurred without much cellular infiltration, and the resultant picture of disappearance of capsule and tuft and its replacement by loose fibrous tissue corresponded exactly with the picture of the glomeruli in the present case. This finding might 
suggest that the case was one of polyarteritis nodosa in which there was no tissue reaction to the lesion, but this contention is not tenable when it is realized that all the glomeruli were affected equally and almost simultaneously and that there were no lesions of polyarteritis in vessels of the kidney itself nor of any other organ.

The finding, in these three cases of polyarteritis nodosa, that a small proportion of glomeruli showed an atypical "lytic" lesion induced consideration of the larger groups of experimental serum nephritis and of glomerulonephritis itself. In experimental glomerulonephritis produced by specific sera as described by Arnott, Kellar, and Matthew (1936), in confirmation of the work done in Faber's laboratories by Masugi, Sato, and others, all the glomerular lesions were productive in nature, with swelling of the endothelial and epithelial cells, proliferation of the epithelial cells to form epithelial crescents and ultimately dense fibrosis occurred in the tufts: all glomeruli were not affected to the same degree; the tubules also showed fatty and hyaline droplet degenerative changes. In the present case, the glomerular lesion was not productive but lytic in nature, with disappearance of endothelial and epithelial cells, and ultimately a very loose fibrosis occupied the place of the missing structures ; the tubules did not show the same degenerative changes.

The same line of reasoning indicated that the lesion in the present case was not of the same type as the ordinary acute glomerulonephritis (Russell, 1929; Hadfield and Garrod, 1947), and this was clearly shown in a case of anuria, reported by Richards and Gibson (1953), where Bull's therapy had maintained the patient's life for the same duration (25 days) as the present, yet the lesions in the kidney showed the same productive lesions as would be found in a case where life had not been so prolonged or death occurred for other reasons without anuria. Nevertheless, sections were examined from 26 cases of acute, subacute, and chronic glomerulonephritis to see if any glomeruli had undergone this lytic destruction. In 24 cases, there was no evidence of any stages resembling those found in the present case. In one case, accepted by the late Professor J. Shaw Dunn as a subacute mixed intra- and extra-capillary glomerulonephritis, a small proportion of glomeruli were showing lytic changes, leaving the loose fibrous tissue as found here. In one further case, a girl of 6 years who had had four previous attacks of nephritis, the last a year before the final attack, the glomeruli were greatly reduced inos? number, were considerably enlarged and showedo only recent signs of acute mixed intra- and slighto extra-capillary glomerulonephritis with no evi-क dence of old damage, the whole picture suggesting that previous attacks had caused complete loss of many glomeruli, possibly by some lytic process? in the present case.

In view of the facts (1) that the dermatologist suspected this case as being an unusual type of sensitivity reaction, possibly to aspirin (one of an comparatively small number of drugs in common. use which produces such a skin eruption in sensitive individuals), and (2) that it was only in poly $-\rightarrow$ arteritis nodosa and glomerulonephritis that even a few examples of this lytic lesion of glomerulio was found, it seems reasonable to consider it as an unusual type of sensitivity lesion. The fact that it has not been recognized previously would indi cate that it is a relatively rare variety, but this may $\vec{c}$ be due to its own self-effacement in a fairly earlye stage, and it may be recognized in the future in early cases of other sensitivity reactions.

\section{Summary}

A case of anuria with an unusual kidney lesiono is described and discussed.

It is suggested that the glomerular lesion is a흘 rare type of sensitivity reaction.

The author wishes to express his sincere thanks to. Drs. J. Basil Rennie, physician, A. Girdwood Fergus son, dermatologist, and J. Wilson Chambers, bio? chemist, for their clinical notes and helpful co 3 operation; to Professor J. Henry Dible (Postgraduate School of Medicine, London) for his opinion on the sections and suggestions as to conditions to be con₹ sidered; and to Mr. Ian Mackie for the photographs?

\section{REFERENCES}

Arnott, W. M., Kellar, R. J., and Matthew, G. D. (1936). EdinbN med. $J_{.,}, 43,233$.

Bull, G. M.'(1952). Proc. roy. Soc. Med., 45, 848.
and Dible, J. H. (1953). In Recent Advances in Pathology 6 th ed., pp. 281-308. Edited by G. Hadfield. Churchilis London.

Davson, J., Ball, J., and Platt, R. (1948). Quart. J. Med., n.s., 17, 175 Dunn, J. S., and Montgomery, G. L. (1941). J. Path. Bact., 52, 1 Gold, S. C., and Gowing, N. F. C. (1953). Quart. J. Med., n.s., 220 old, $\mathrm{S}$.

Hadfield, G., and Garrod, L. P. (1947). Recent Advances in Pathoథ logy, 5th ed., pp. 279-303. Churchill, London.

Richards, R. L., and Gibson, J. B. (1953). Glasg. med. J., 34, 126. Russell, D. S. (1929). Spec. Rep. Ser. med. Res. Coun. (Lond.), No, 142 .

Smith, J. F. (1955). J. Path. Bact., 70, 41.

Solomon, C., Roberts, J. E., and Lisa, J. R. (1942). Amer. J. Path

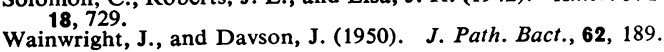

